\title{
Características de carcaça de cordeiros em pastagem de azevém manejada em diferentes alturas
}

\author{
Paulo César de Faccio Carvalho(1), José Otavio Rocha Oliveira(2), Laíse da Silveira Pontes ${ }^{(3)}$, \\ Emanuel Orestes da Silveira ${ }^{(4)}$, César Henrique Espírito Candal Poli( ${ }^{(5)}$, Jane Maria Rübensam ${ }^{(1)}$ \\ e Rogério Jaworski dos Santos ${ }^{(1)}$
}

\begin{abstract}
(1)Universidade Federal do Rio Grande do Sul, Av. Bento Gonçalves, № 7.712, Agronomia, CEP 91501-970 Porto Alegre, RS E-mail: paulocfc@ufrgs.br, jane@adufrgs.ufrgs.br, jaworskirs@yahoo.com.br (2)Av. Amintas Maciel 336/402, CEP 99700-000 Erechim, RS. E-mail: zeotavio@via-rs.net (3)Institut National de la Recherche Agronomique, Unité d'Agronomie, INRA, 234, Av. du Brezet, Clermont-Ferrand, F-63039 Cedex 02, France. E-mail: Ipontes@sancy.clermont.inra.fr (4)Rua Santina Manzoque Zen, no 20, casa 1, CEP 83020-280 São José dos Pinhais, PR. E-mail: forrageiro@hotmail.com ${ }^{(5)}$ Embrapa Pecuária Sul, BR 153, Km 595, Caixa Postal 242, CEP 96401-970 Bagé, RS. E-mail: cpoli@cnpf.embrapa.br
\end{abstract}

\begin{abstract}
Resumo - O objetivo deste trabalho foi avaliar as características de carcaça, de cordeiros mantidos em pastagem de azevém anual (Lolium multiflorum Lam.) manejada em diferentes alturas (5, 10, 15 e $20 \mathrm{~cm}$ ), sob lotação contínua com carga variável, no período de agosto a novembro de 1999. Utilizou-se um delineamento em blocos ao acaso, com três repetições, e as variáveis estudadas foram submetidas à análise de regressão. Os pesos de abate, carcaça quente, filé mignon, paleta e costela diferiram entre os tratamentos e foram inferiores no tratamento relativo à altura de manejo de $5 \mathrm{~cm}$, quando comparados aos tratamentos de 10,15 e $20 \mathrm{~cm}$, que não diferiram entre si. Não houve diferença entre tratamentos para os pesos de pernil e de carré. O rendimento de carcaça variou

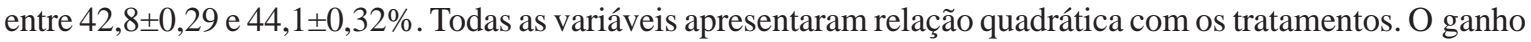
médio diário influenciou diretamente o peso de abate que, por sua vez, correlacionou fortemente com o rendimento e o peso da carcaça. Os resultados mostram que os melhores rendimentos dos cortes comerciais de cordeiros são obtidos quando a pastagem de azevém é manejada no intervalo entre 12 e 14 cm de altura.
\end{abstract}

Termos para indexação: Lolium multiflorum, cortes de carcaça, desempenho animal, pastejo, peso de abate, rendimento de carcaça.

\section{Carcass characteristics of lambs kept on ryegrass pasture managed at different sward heights}

\begin{abstract}
The objective of this work was to evaluate the carcass characteristics of lambs maintained on ryegrass (Lolium multiflorum Lam.) pastures managed with different heights $(5,10,15$ and $20 \mathrm{~cm}$ ), under continuous variable stocking, from August to November 1999. A randomized block design with three replicates was used. The slaughter weight, hot carcass, fillet, palette and rib weights were different among treatments, and those related to the height $5 \mathrm{~cm}$ were lower than the ones of 10,15 and $20 \mathrm{~cm}$, which were not different among them. There were no differences for hind leg and rib loin. Carcass yield ranged from $42.8 \pm 0.29$ and $44.1 \pm 0.32 \%$. All variables showed a quadratic relationship to treatments. The daily liveweight gain determined directly the liveweight at slaughter, the latter being strongly correlated to carcass yield and weight. Better yield of lamb carcass cuts were obtained when ryegrass was managed between 12 and $14 \mathrm{~cm}$ height.
\end{abstract}

Index terms: Lolium multiflorum, carcass cuts, animal performance, grazing, slaughter weight, carcass yield.

\section{Introdução}

A ovinocultura gaúcha vem buscando sua reestruturação pela produção de carne (Pereira Neto, 2004). Tal atividade, que é perfeitamente compatível com a produção de lã, apresenta como vantagens o curto período de gestação da ovelha, a alta taxa de prolificidade e o grande potencial de crescimento do cordeiro, que fazem com que, num período inferior a um ano, se possa ir da concepção ao abate, o que resulta em maior giro de capital.

Segundo Motta et al. (2001), a eficiência na produção de carne, com máximo de músculo e adequada quantidade de gordura, é o objetivo dos sistemas modernos de produção. A época de venda e as características da carcaça são aspectos importantes a serem considerados nesse mercado, a fim de se obterem bons preços e para se conquistar o mercado consumidor. Para aumentar 
o consumo da carne de cordeiro, melhoramentos substanciais na eficiência e composição da carcaça também são necessários. A idade muita avançada dos animais e dietas que propiciem elevada deposição de gordura são aspectos a serem evitados pelos produtores. $\mathrm{O}$ processo de terminação dos cordeiros é um desafio e uma das etapas mais limitantes da cadeia produtiva, por isso é de necessidade premente a sua melhoria com vistas ao progresso da ovinocultura (Pereira Neto, 2004).

Um dos principais fatores a serem destacados nessa atividade são os diferentes cortes que compõem uma carcaça (Motta et al., 2001), pois possuem valores distintos. A proporção de cada corte constitui em importante critério na avaliação comercial da carcaça. Osório et al. (1996a) concluíram que para se determinar a qualidade total do animal para abate, deve-se levar em consideração, além do peso e rendimento da carcaça, os outros componentes do peso vivo, que podem variar de acordo com os genótipos e os fatores do meio. Por isso, estudos sobre fatores que agem na formação da carcaça, com vistas a produzir um produto condizente com as exigências do mercado, são necessários para alicerçar e orientar os sistemas de produção.

No que diz respeito a sistemas de produção baseados no uso de pastagens, é preciso definir um manejo que não somente otimize a colheita de forragem pelo animal em pastejo, mas que também potencialize a produção de carcaças de qualidade, inserindo-se no sistema de produção uma preocupação direta com o mercado consumidor (Prache et al., 2005). Nesse intuito, testou-se a hipótese de que diferentes oportunidades de ingestão de nutrientes, representadas por diferentes alturas do azevém, afetariam as características da carcaça dos cordeiros.

Este trabalho teve por objetivo avaliar as principais características da carcaça de cordeiros mantidos em pastagens de azevém anual manejadas em alturas de 5, 10,15 ou $20 \mathrm{~cm}$.

\section{Material e Métodos}

O experimento foi conduzido na Estação Experimental Agronômica da Universidade Federal do Rio Grande do Sul (EEA-UFRGS). A EEA localiza-se a $30^{\circ} 5^{\prime}$ 'S e 51 $1^{\circ} 40^{\prime} \mathrm{W}$, à altitude de $46 \mathrm{~m}$, no Município de Eldorado do Sul, RS. O clima, segundo a classificação de Köppen, é do tipo Cfa (subtropical úmido, com verão quente). Apresenta temperatura média mensal que varia de 14,2 a $24,9^{\circ} \mathrm{C}$ e precipitação média em torno de 1.440 mm anuais. $\mathrm{O}$ solo está clas- sificado como Plintossolo Argilúvico distrófico (FTd), segundo Embrapa (1999).

A área experimental, constituída de 4,98 ha, foi dividida em 12 piquetes. A pastagem foi semeada em sistema de plantio direto, com renovadora de pastagem, em 28/5/99, na densidade de $40 \mathrm{~kg} \mathrm{ha}^{-1}$ de sementes de azevém anual (Lolium multiflorum Lam.), e foi adubada com $20 \mathrm{~kg} \mathrm{ha}^{-1}$ de $\mathrm{N}$ (uréia), $70 \mathrm{~kg} \mathrm{ha}^{-1}$ de $\mathrm{P}_{2} \mathrm{O}_{5}$ (superfosfato triplo) e $15 \mathrm{~kg} \mathrm{ha}^{-1}$ de $\mathrm{K}_{2} \mathrm{O}$ (cloreto de potássio). Foram feitas aplicações de $\mathrm{N}$ em cobertura, com $138 \mathrm{~kg} \mathrm{ha}^{-1}$ no dia 30/6/1999 e $68 \mathrm{~kg} \mathrm{ha}^{-1}$ no dia 10/9/1999. Os tratamentos consistiram na manutenção de quatro alturas de manejo do pasto: 5, 10, 15 e 20 cm. Para manutenção das alturas pretendidas, utilizou-se a técnica de lotação variável, descrita em Pontes et al. (2004), em lotação contínua, com número variável de animais reguladores.

O delineamento experimental utilizado foi o de blocos ao acaso, com três repetições. Os animais experimentais foram cordeiros cruzados das raças Texel (CG1 e CG3) e Île-de-France, todos inteiros, com idade média aproximada de um ano e com peso médio inicial de $36,1 \pm 4,5 \mathrm{~kg}$.

Cada piquete contou com 11 animais-teste, dos quais se originaram as variáveis de desempenho. Os animais foram distribuídos nos piquetes, balanceados segundo suas diferentes características genéticas, num total de 132 cordeiros, mais um número variável de animais reguladores. Os animais foram pesados a cada 21 dias (sempre no mesmo horário), e após jejum de 12 horas somente antes das pesagens inicial e final do experimento, que foram usadas para estimar o ganho médio diário e o ganho por hectare. As pesagens intermediárias serviram para orientar os ajustes de lotação necessários, bem como para controlar o desempenho animal.

Foi utilizada uma área adicional de azevém (1,02 ha), para manter os animais reguladores nos períodos em que não estavam sendo utilizados nas unidades experimentais. O período de utilização da pastagem foi de 19/8/1999 a 11/11/1999, num total de 88 dias. Periodicamente, os animais foram vermifugados e passados no pedilúvio para o controle da manqueira. Sal mineral e água foram fornecidos à vontade.

Semanalmente, media-se a altura do pasto, em 100 pontos por unidade experimental, com o auxílio de um bastão graduado. Por altura do pasto considerou-se a altura média do toque do bastão nas folhas mais superiores do dossel. Para obtenção da massa de 
forragem, amostragens foram realizadas a cada 21 dias, a partir de leituras aleatórias da vegetação por meio do método do disco (Silva \& Cunha, 2003). Pelo menos 50 leituras foram realizadas por unidade experimental. O valor médio observado em cada piquete foi usado como variável independente em regressão linear, em que os coeficientes foram gerados a partir dos valores da altura do disco e da quantidade de forragem coletada por amostra destrutiva (Moraes, 1991). Para tanto, foram utilizados três cortes por unidade experimental, realizados a cada 21 dias.

As amostras de $0,25 \mathrm{~m}^{2}$ cada, cortadas rente ao solo, foram posteriormente separadas nos componentes: lâminas foliares verdes, colmos juntamente com bainhas e material morto. Essas amostras foram levadas a uma estufa com circulação forçada de ar, à temperatura de $65^{\circ} \mathrm{C}$, até atingirem massa constante, e depois foram pesadas em balança com precisão de $1 \mathrm{~g}$ para a determinação da matéria seca (MS). Uma vez obtida a quantidade de lâminas foliares disponíveis na pastagem, e conhecendo a carga média utilizada para manutenção das alturas de cada tratamento, calculou-se a oferta de lâminas foliares por animal, expressando-a em relação ao peso vivo (PV), usando-se a mesma metodologia descrita em Moraes (1991).

Os animais ingressaram na pastagem em 19/8/99, quando esta apresentava uma altura de $25 \mathrm{~cm}$. Houve um ajuste da lotação inicial e, depois de 27 dias, as alturas pretendidas foram atingidas (Pontes et al., 2003).

Ao término do período de utilização da pastagem, todos os animais foram pesados, tendo sido abatidos oito animais de cada unidade experimental (seis animais CG1 e dois CG3 de cada piquete, conforme regulamento descrito em Brasil (1997). Depois do abate, as carcaças foram pesadas para obtenção do rendimento, e foram resfriadas por 24 horas a $4^{\circ} \mathrm{C}$. Em seguida, foi realizada a divisão da carcaça nos seguintes cortes comerciais: paleta, pernil, costela, filé mignon e carré, procedendose à pesagem em balança com precisão de $1 \mathrm{~g}$. A paleta é uma peça obtida por secção dos músculos, em torno das regiões escapular e braquial. O pernil é uma peça obtida do quarto traseiro, seccionado longitudinalmente ao nível do osso sacro, após a retirada das massas musculares pertencentes à costela. A costela é um corte constituído das massas musculares e bases ósseas correspondentes às costelas, a última esternebra, o apêndice xifóide e a região do vazio, limitando-se em suas porções superior com o lombo e inferior com o peito. O filé mignon é um corte constituído das massas musculares aderidas à face ventral das três últimas vértebras torácicas, seis lombares, ilíaco e fêmur. O carré é o corte constituído das massas musculares lombares situadas entre o pescoço e o pernil, limitado em sua porção ventral com o corte da costela.

Realizou-se o teste de médias (Lsmeans) pelo procedimento GLM do SAS (SAS Institute, 1996). Posteriormente, foi realizada análise de regressão entre as variáveis, em estudo com as alturas reais e ofertas de lâminas foliares, obtidas pelo procedimento PROCGLM do mesmo aplicativo.

\section{Resultados e Discussão}

Na Tabela 1, estão descritas as características referentes à condição do pasto e ao desempenho dos animais, durante o período de utilização. As diferenças de altura, entre tratamentos, ocasionaram diferenças nas massas de forragem observadas nos tratamentos, na mesma proporção. Essas massas de forragem variaram entre 1.416 e $3.140 \mathrm{~kg} \mathrm{ha}^{-1}$ de MS. Com relação à massa de forragem, Poppi (1983) afirma que o consumo de forragem de cordeiros é maximizado em pastos densos e folhosos de espécies temperadas, com massa de forragem de $1.800 \mathrm{~kg} \mathrm{ha}^{-1}$ de MS. Massas muito inferiores a esses valores podem ocasionar restrição ao consumo dos animais, por características associadas à estrutura do pasto, a exemplo do explicado por Prache (1997) e Carrère et al. (2001), condição observada somente no tratamento com altura de manejo da pastagem de $5 \mathrm{~cm}$.

Tabela 1. Variáveis do pasto e desempenho animal de cordeiros, em pastagem de azevém anual, manejada em diferentes alturas(1).

\begin{tabular}{lcccc}
\hline Parâmetro & $5 \mathrm{~cm}$ & $10 \mathrm{~cm}$ & $15 \mathrm{~cm}$ & $20 \mathrm{~cm}$ \\
\hline Altura do pasto (cm) & $9 \pm 0,7 \mathrm{c}$ & $12 \pm 0,5 \mathrm{~b}$ & $14 \pm 0,5 \mathrm{~b}$ & $18 \pm 0,9 \mathrm{a}$ \\
Massa de forragem (kg ha $\left.{ }^{-1} \mathrm{de} \mathrm{MS}\right)$ & $1.417 \pm 84 \mathrm{c}$ & $2.154 \pm 131 \mathrm{~b}$ & $2.104 \pm 75 \mathrm{~b}$ & $3.141 \pm 229 \mathrm{a}$ \\
Oferta de lâminas verdes (\% do PV) & $5 \pm 0,78 \mathrm{~b}$ & $6 \pm 0,2 \mathrm{~b}$ & $10 \pm 1,04 \mathrm{a}$ & $12 \pm 0,96 \mathrm{a}$ \\
Ganho médio diário por animal (kg dia ${ }^{-1} \mathrm{de} \mathrm{PV)}$ & $0,113 \pm 0,04 \mathrm{~b}$ & $0,219 \pm 0,009 \mathrm{a}$ & $0,221 \pm 0,011 \mathrm{a}$ & $0,236 \pm 0,006 \mathrm{a}$ \\
Ganho por área $\left(\mathrm{kg} \mathrm{ha}^{-1} \mathrm{de} \mathrm{PV)}\right.$ & $240 \pm 87 \mathrm{c}$ & $662 \pm 77 \mathrm{ab}$ & $480 \pm 96 \mathrm{bc}$ & $461 \pm 112 \mathrm{bc}$ \\
Carga animal $\left(\mathrm{kg} \mathrm{ha}^{-1} \mathrm{de} \mathrm{PV}\right)$ & $2.036 \pm 110 \mathrm{a}$ & $1.534 \pm 98 \mathrm{~b}$ & $1.413 \pm 122 \mathrm{bc}$ & $1.033 \pm 142 \mathrm{c}$ \\
\hline
\end{tabular}

${ }^{(1)}$ Médias, com respectivo erro-padrão, seguidas de letras iguais, na linha, não diferem entre si pelo teste Lsmeans a 5\% de probabilidade. 
A oferta de lâminas foliares verdes é decorrente dos diferentes tratamentos impostos à pastagem. Segundo Hodgson (1990), a ingestão por animais em pastejo é limitada, quando a oferta de forragem é inferior a duas vezes o potencial de consumo dos animais. Esta condição somente foi observada no tratamento $5 \mathrm{~cm}$, onde a oferta de forragem foi de 6,3\% do PV, tendo os outros tratamentos ofertas superiores a $9 \%(9,7,13,7$ e $19,6 \%$, para os tratamentos 10,15 e $20 \mathrm{~cm}$, respectivamente).

A análise de variância, referente ao ganho médio diário (GMD), demonstrou inferioridade do tratamento $5 \mathrm{~cm}$ em relação aos tratamentos 10, 15 e $20 \mathrm{~cm}$, que não diferiram entre si. As alturas 10, 15 e $20 \mathrm{~cm}$ foram aquelas cujas ofertas foram superiores à indicação de limitação de consumo. Canto et al. (1999) observaram ganhos de peso máximos de 122 g por dia em pastagem de azevém e trevo-branco, valores estes inferiores aos observados neste trabalho. Segundo Rattray et al. (1987), há uma relação quadrática e positiva entre GMD e oferta de forragem. Esses autores descreveram que, para animais com peso médio de $40 \mathrm{~kg}$, o GMD atinge um máximo de $100 \mathrm{~g}$ por dia em ofertas de matéria seca da ordem de $10 \%$ do PV. Neste trabalho o GMD máximo foi obtido em ofertas semelhantes a esta, porém, o GMD foi substancialmente superior.

Os ganhos de peso vivo por unidade de área variaram de 240 a $662 \mathrm{~kg} \mathrm{ha}^{-1}$, como reflexo dos GMD e das cargas utilizadas durante o período experimental. O tratamento $10 \mathrm{~cm}$ chegou a alcançar produção diária de $7,8 \mathrm{~kg} \mathrm{ha}^{-1}$ de PV. O melhor tratamento no trabalho de Canto et al. (1999) apresentou taxa diária de $7,1 \mathrm{~kg} \mathrm{ha}^{-1}$ de PV, pouco inferior ao observado neste trabalho.

Na Tabela 2, estão descritas as características quantitativas da carcaça. Cordeiros mantidos em pastagem de azevém com $5 \mathrm{~cm}$ de altura apresentaram pesos de abate, carcaça quente, filé mignon, paleta e costela inferiores aos demais tratamentos. Como o tratamento $5 \mathrm{~cm}$ é aquele que havia limitação de consumo, isto se refletiu nos cortes comerciais, exceção feita aos pesos do pernil e do carré. O rendimento de carcaça dos cordeiros do tratamento $5 \mathrm{~cm}$ foi inferior ao dos cordeiros dos tratamentos 10 e $15 \mathrm{~cm}$ de altura. Os pesos dos componentes da carcaça estão de acordo com os valores encontrados na literatura (Osório et al., 1999).

Os resultados obtidos para o GMD (Y $=-517,363+$ 98,8329x - 3,1922 $x^{2} ; r^{2}=0,72$ ) se refletiram nas características da carcaça. Todas as variáveis apresentaram resposta quadrática, em relação às alturas da pastagem e à oferta de lâminas foliares verdes. Na Tabela 3, observam-se as equações de regressão, os coeficientes de determinação e as probabilidades, de cada variável associada à carcaça dos cordeiros. Os coeficientes de determinação in-

Tabela 2. Características da carcaça de cordeiros em pastagem de azevém anual, manejada em diferentes alturas ${ }^{(1)}$.

\begin{tabular}{lccc}
\hline Característica & $5 \mathrm{~cm}$ & $10 \mathrm{~cm}$ & $15 \mathrm{~cm}$ \\
\hline Peso de abate $(\mathrm{kg})$ & $46,7 \pm 1,9 \mathrm{~b}$ & $54,3 \pm 1,7 \mathrm{a}$ & $55,0 \pm 2,1 \mathrm{a}$ \\
Peso de carcaça $(\mathrm{kg})$ & $19,9 \pm 0,8 \mathrm{~b}$ & $23,8 \pm 0,7 \mathrm{a}$ & $24,3 \pm 0,9 \mathrm{a}$ \\
Rendimento de carcaça quente $(\%)$ & $42,8 \pm 0,3 \mathrm{~b}$ & $43,8 \pm 0,3 \mathrm{a}$ & $44,1 \pm 0,3 \mathrm{a}$ \\
Peso do filé mignon $(\mathrm{kg})$ & $0,234 \pm 0,006 \mathrm{~b}$ & $0,276 \pm 0,005 \mathrm{a}$ & $0,278 \pm 0,007 \mathrm{a}$ \\
Peso da paleta $(\mathrm{kg})$ & $2,11 \pm 0,0067 \mathrm{~b}$ & $2,39 \pm 0,059 \mathrm{a}$ & $2,46 \pm 0,074 \mathrm{a}$ \\
Peso do pernil $(\mathrm{kg})$ & $3,18 \pm 0,087 \mathrm{a}$ & $3,59 \pm 0,077 \mathrm{a}$ & $3,73 \pm 0,097 \mathrm{a}$ \\
Peso da costela $(\mathrm{kg})$ & $1,37 \pm 0,067 \mathrm{~b}$ & $1,83 \pm 0,060 \mathrm{a}$ & $1,89 \pm 0,074 \mathrm{a}$ \\
Peso do carré $(\mathrm{kg})$ & $1,47 \pm 0,044 \mathrm{a}$ & $1,77 \pm 0,039 \mathrm{a}$ & $2,41 \pm 0,086 \mathrm{a}$ \\
\hline
\end{tabular}

(1)Médias, com respectivo erro-padrão, seguidas de letras iguais, na linha, não diferem entre si pelo teste Lsmeans a 5\% de probabilidade.

Tabela 3. Equações de regressão, coeficientes de determinação e valores de probabilidade, das características da carcaça de cordeiros, em resposta às diferentes alturas de manejo do pasto e à oferta de lâminas foliares de azevém.

\begin{tabular}{lll}
\hline Característica & \multicolumn{1}{c}{ Altura do pasto $(\mathrm{cm})$} & \multicolumn{1}{c}{ Oferta de lâminas (\%) } \\
Peso de abate $(\mathrm{kg})$ & $\mathrm{Y}=31,45+3,87 \mathrm{X}-0,15 \mathrm{X}^{2} ; \mathrm{r}^{2}=0,66 ; \mathrm{p}=0,0074$ & $\mathrm{Y}=33,59+6,05 \mathrm{X}-0,42 \mathrm{x}^{2} ; \mathrm{r}^{2}=0,70 ; \mathrm{p}=0,0044$ \\
Peso de carcaça quente $(\mathrm{kg})$ & $\mathrm{Y}=11,82+2,07 \mathrm{X}-0,08 \mathrm{X}^{2} ; \mathrm{r}^{2}=0,70 ; \mathrm{p}=0,0046$ & $\mathrm{Y}=13,04+3,21 \mathrm{X}-0,23 \mathrm{X}^{2} ; \mathrm{r}^{2}=0,72 ; \mathrm{p}=0,0035$ \\
Rendimento de carcaça $(\%)$ & $\mathrm{Y}=39,96+0,74 \mathrm{X}-0,033 \mathrm{X}^{2} ; \mathrm{r}^{2}=0,49 ; \mathrm{p}=0,047$ & $\mathrm{Y}=40,45+1,11 \mathrm{X}-0,09 \mathrm{X}^{2} ; \mathrm{r}^{2}=0,39 ; \mathrm{p}=0,1077$ \\
Peso de filé mignon $(\mathrm{g})$ & $\mathrm{Y}=152,73+20,29 \mathrm{X}-0,77 \mathrm{X}^{2} ; \mathrm{r}^{2}=0,61 ; \mathrm{p}=0,0151$ & $\mathrm{Y}=178,35+24,44 \mathrm{X}-0,43 \mathrm{X}^{2} ; \mathrm{r}^{2}=0,63 ; \mathrm{p}=0,0112$ \\
Peso de paleta $(\mathrm{g})$ & $\mathrm{Y}=1442,34+167,19 \mathrm{X}-6,75 \mathrm{X}^{2} ; \mathrm{r}^{2}=0,63 ; \mathrm{p}=0,0118$ & $\mathrm{Y}=1560,43+251,23 \mathrm{X}-17,77 \mathrm{X}^{2} ; \mathrm{r}^{2}=0,62 ; \mathrm{p}=0,0129$ \\
Peso do pernil $(\mathrm{g})$ & $\mathrm{Y}=2186,39+251,76 \mathrm{X}-10,26 \mathrm{X}^{2} ; \mathrm{r}^{2}=0,65 ; \mathrm{p}=0,0085$ & $\mathrm{Y}=2358,29+383,68 \mathrm{X}-27,63 \mathrm{X}^{2} ; \mathrm{r}^{2}=0,63 ; \mathrm{p}=0,0110$ \\
Peso da costela $(\mathrm{g})$ & $\mathrm{Y}=510,30+218,33 \mathrm{X}-8,35 \mathrm{X}^{2} ; \mathrm{r}^{2}=0,82 ; \mathrm{p}=0,0005$ & $\mathrm{Y}=668,33+324,76 \mathrm{X}-21,54 \mathrm{X}^{2} ; \mathrm{r}^{2}=0,85 ; \mathrm{p}=0,0002$ \\
Peso do carré $(\mathrm{g})$ & $\mathrm{Y}=825,85+161,27 \mathrm{X}-6,90 \mathrm{X}^{2} ; \mathrm{r}^{2}=0,76 ; \mathrm{p}=0,0017$ & $\mathrm{Y}=988,69+218,93 \mathrm{X}-13,82 \mathrm{X}^{2} ; \mathrm{r}^{2}=0,76 ; \mathrm{p}=0,0017$ \\
\hline
\end{tabular}


dicaram que uma variação acima de $60 \%$, no peso médio da maioria dos cortes, é explicada pela altura ou pela oferta de lâminas foliares.

$\mathrm{O}$ peso de abate correlacionou-se, de forma linear e positiva, com o peso da carcaça $\left(\mathrm{R}=0,98\right.$; $\mathrm{r}^{2}=0,97$; $\mathrm{p}<0,01 ; \hat{\mathrm{Y}}=-3,12+0,50 \mathrm{X})$, a exemplo do reportado por Wylie et al. (1997). O maior peso de carcaça corresponde ao peso mais elevado de abate, o que está de acordo com Motta et al. (2001). Essa clássica relação positiva, entre o peso vivo e o peso da carcaça, sugere o uso do peso vivo pelos produtores para a realização da seleção de animais para o abate, sejam de uma mesma raça ou geneticamente semelhantes. O peso máximo de abate foi obtido à altura de manejo da pastagem estimada em $12,7 \mathrm{~cm}$ e com oferta de lâminas foliares de 7,2\%. Destaca-se o fato de que pequenas mudanças na altura ou oferta de lâminas foliares resultaram em grandes alterações no peso final dos cordeiros.

Os pesos de carcaça quente (PCQ) foram elevados para cordeiros (Tabela 2). O que pode ter contribuído para esses valores foi o grau de maturidade avançado dos animais, para a categoria cordeiro, pois muitos já estavam próximos de trocar e outros já estavam trocando dentes por ocasião do abate. Ribeiro et al. (2000) obtiveram um PCQ médio de 18,3 kg, de animais inteiros Île-de-France, com 12 meses de idade, mantidos exclusivamente no pasto. Nicoll et al. (1998), ao estudar o efeito de diferentes genótipos, obtiveram valores de PCQ de 23,2 kg para a raça Texel aos 10,5 meses de idade, similares aos encontrados neste trabalho. Para a efetiva comparação entre resultados, é importante levar em consideração fatores como período de jejum, distância percorrida até o frigorífico, condições ambientais, condições de transporte, entre outros (Osório et al., 1996b).

Quanto ao rendimento de carcaça quente (RCQ), os resultados encontrados foram similares aos obtidos por Osório et al. (1999). Esses autores obtiveram RCQ de 43,2 e 43,3\% em cordeiros castrados e inteiros, respectivamente, criados em condições extensivas de campo nativo e abatidos aos cinco meses de idade. Os resultados encontrados são valores esperados para animais criados exclusivamente no pasto, ou seja, menores que $50 \%$, em razão do maior desenvolvimento do trato digestório (Ribeiro et al., 2000).

Assim como o peso de abate e de carcaça quente, os pesos dos cortes também apresentaram variações semelhantes. Pequenos aumentos na altura do pasto acarretaram significativos aumentos na produção de cortes nobres, como o do filé mignon, que apresentou peso máximo de $0,286 \mathrm{~kg}$, em alturas de pastagem próximas a $13 \mathrm{~cm}$. Todos os demais cortes foram maximizados no intervalo de 12 a $14 \mathrm{~cm}$ de altura do pasto e de 7 a 8\% de oferta de lâminas foliares verdes. O modelo referente à relação entre o peso da costela e a altura do pasto $\left(r^{2}=0,82\right)$ ou oferta de lâminas foliares $\left(r^{2}=0,85\right)$ foi o que apresentou o melhor ajuste. Aumentos substanciais no peso da costela ocorreram à medida que a altura do pasto era maior. Seis centímetros de diferença na altura do pasto foram equivalentes a um aumento de $0,5 \mathrm{~kg}$ no peso da costela.

Portanto, a altura de manejo do pasto interferiu no rendimento e na qualidade do produto final, pois ao se determinar o nível de ingestão de forragem (Baumont et al., 2004), a altura de manejo determinou, indiretamente, a quantidade de nutrientes disponíveis para serem convertidos em produto animal. Em baixas alturas, como no tratamento $5 \mathrm{~cm}$, o desempenho dos animais foi restringido tanto pela oferta de forragem como pela sua dificuldade de apreensão (Poppi et al., 1987). Rattray et al. (1987) afirmaram que isso pode ocorrer em massas de forragem inferiores a $2.000 \mathrm{~kg} \mathrm{ha}^{-1}$ de MS. No outro extremo $(20 \mathrm{~cm})$, em alturas demasiadamente elevadas, a diminuição no rendimento dos cortes estaria associada às características qualitativas e estruturais da pastagem (Poppi et al., 1987), como a menor proporção de lâminas foliares, que resultaria na diminuição da profundidade do bocado e no aumento do tempo necessário à formação do bocado, representado pela procura e apreensão de lâminas foliares verdes (Palhano et al., 2002).

\section{Conclusões}

1. A altura de manejo do pasto afeta o rendimento dos cortes; pequenas variações na altura de manejo têm forte impacto sobre a produção de cordeiros.

2. A altura que proporciona maiores ganhos de peso dos animais também ocasiona o aumento do rendimento dos cortes comerciais; todos os cortes comerciais estudados apresentam uma relação quadrática positiva com as variáveis altura do pasto e oferta de lâminas foliares verdes.

3. A maximização das características quantitativas da carcaça ocorre no intervalo entre 12 e $14 \mathrm{~cm}$ de altura do pasto, e em ofertas de lâminas foliares verdes correspondentes a 7 e $8 \%$ do peso vivo. 


\section{Agradecimentos}

À Fapergs, pelo auxílio financeiro; ao CNPq pela concessão de bolsas de estudos; à Agropecuária Cerro Coroado, por ceder os animais e prover as condições de pesquisa.

\section{Referências}

BAUMONT, R.; COHEN-SALMON, D.; PRACHE, S.; SAUVANT, D. A mechanistic model of intake and grazing behaviour in sheep integrating sward architecture and animal decisions. Animal Feed Science and Technology, v.112, p.5-28, 2004.

BRASIL. Ministério da Agricultura, Pecuária e Abastecimento. Regulamento de inspeção industrial e sanitária de produtos de origem animal. Brasília, 1997. 241p.

CANTO, M.W. do; MOOJEN, E.L.; CARVALHO, P.C. de F.; SILVA, J.H.S. Produção de cordeiros em pastagem de azevém e trevo branco sob diferentes níveis de resíduos de forragem. Pesquisa Agropecuária Brasileira, v.34, p.309-316, 1999.

CARRÈRE, P.; LOUAULT, F.; CARVALHO, P.C. de F.; LAFARGE, M.; SOUSSANA, J.F. How does the vertical and horizontal structure of a perennial ryegrass and white grass clover sward influence grazing? Grass and Forage Science, v.56, p.118-130, 2001.

EMBRAPA. Centro Nacional de Pesquisa de Solos (Rio de Janeiro, RJ). Sistema brasileiro de classificação de solos. Rio de Janeiro, 1999. 412p.

HODGSON, J.G. Grazing management: science into practice. New York: Wiley, 1990. 203p.

MORAES, A. Produtividade animal e dinâmica de uma pastagem de pangola (Digitaria decumbens Stent), azevém (Lolium multiflorum Lam.) e trevo-branco (Trifolium repens L.) submetida a diferentes pressões de pastejo. 1991. 200p. Tese (Doutorado) Universidade Federal do Rio Grande do Sul, Porto Alegre.

MOTTA, O.S.; PIRES, C.C.; SILVA, J.H.S.; ROSA, G.T.; FÜLBER, M. Avaliação da carcaça de cordeiros da raça Texel sob diferentes métodos de alimentação e pesos de abate. Ciência Rural, v.31, p.1051-1056, 2001.

NICOLL, G.B.; SKERRIT, J.W.; DOBBIE, J.L.; GRIMWOOD, T.J. Effect of sire genotype on lamb growth and carcass productivity. In: NEW ZEALAND SOCIETY OF ANIMAL PRODUCTION, 58., 1998, Massey. Proceedings. Massey, 1998. p.136-139.

OSÓRIO, J.C. da S.; JARDIM, P.O. da C.; PIMENTEL, M.A.; POUEY, J.; OSÓRIO, M.; LÜDER, W.; BORBA, M. Produção de carne entre cordeiros castrados e não castrados. 1. Cruzas Hampshire Down x Corriedale. Ciência Rural, v.29, p.135-138, 1999.

OSÓRIO, J.C. da S.; OLIVEIRA, N.M. de; JARDIM, P.O.; MONTEIRO, E. Produção de carne em ovinos de cinco genótipos. 2. Componentes do peso vivo. Ciência Rural, v.26, p.471-475, 1996a.
OSÓRIO, J.C. da S.; OLIVEIRA, N.M. de; NUNES, A.P.; POUEY, J. Produção de carne em ovinos de cinco genótipos. 3. Perdas e morfologia. Ciência Rural, v.26, p.477-481, $1996 \mathrm{~b}$.

PALHANO, A.L.; CARVALHO, P.C. de F.; BARRETO, M.Z. Influência da estrutura da pastagem na geometria do bocado e nos processos de procura e manipulação da forragem. Tuiuti, Ciência e Cultura, v.31, p.33-52, 2002.

PEREIRA NETO, O.A. Gerenciamento e capacitação da cadeia da ovinocultura. In: PEREIRA NETO, O.A. (Ed.). Práticas em ovinocultura: ferramentas para o sucesso. Porto Alegre: Solidus, 2004. p.1-8.

PONTES, L. da S.; CARVALHO, P.C. de F.; NABINGER, C.; SOARES, A.B. Fluxo de biomassa em pastagens de azevém anual (Lolium multiflorum Lam.) manejadas em diferentes alturas. Revista Brasileira de Zootecnia, v.33, p.529-537, 2004.

PONTES, L. da S.; NABINGER, C.; CARVALHO, P.C. de F.; TRINDADE, J.K.; MONTARDO, D.P.; SANTOS, R.J. Variáveis morfogênicas e estruturais de azevém anual (Lolium multiflorum Lam.) manejado em diferentes alturas. Revista Brasileira de Zootecnia, v.32, p.814-820, 2003.

POPPI, D.P. Nutrition of the lamb after weaning. In: FAMILTON, A.S. (Ed.). Lamb growth. Hamilton: New Zealand Society of Animal Production, 1983. p.29-42.

POPPI, D.P.; HUGHES, T.P.; L'HUILLIER, P.J. Intake of pasture by grazing ruminants. In: NICOL, A.M. (Ed.). Livestock feeding on pasture. Hamilton: New Zealand Society of Animal Production, 1987. p.55-64. (Occasional publication, 10).

PRACHE, S. Intake rate, intake per bite and time per bite of lactating ewes on vegetative and reproductive swards. Applied Animal Behaviour Science, v.52, p.53-64, 1997.

PRACHE, S.; CORNU, A.; BERDAGUÉ, J.L.; PRIOLO, A. Traceability of animal feeding diet in the meat and milk of small ruminants. Small Ruminant Research, v.59, p.157-168, 2005.

RATTRAY, P.V.; THOMPSON, K.F.; HAWKER, H.; SUMNER, M.R.W. Pastures for sheep production. In: NICOL, A.M. (Ed.). Livestock feeding on pasture. Hamilton: New Zealand Society of Animal Production, 1987. p.89-104. (Occasional publication, 10).

RIBEIRO, E.L.A.; ROCHA, M.A.; MIZUBUTI, I.Y.; MORI, R.M. Ganho de peso e componentes do peso vivo em borregos Ile de France inteiros ou castrados e Hampshire Down castrados abatidos aos doze meses de idade. Ciência Rural, v.30, p.333-336, 2000.

SAS INSTITUTE (Cary, Estados Unidos). SAS/STAT: user's guide. Cary, 1996. 1 disquete.

SILVA, S.C. da; CUNHA, W.F. da. Métodos indiretos para avaliar a massa de forragem em pastos de Cynodon spp. Pesquisa Agropecuária Brasileira, v.38, p.981-989, 2003.

WYLIE, A.R.G.; CHESTNUTT, D.M.B.; KILPATRICK, D.J. Growth and carcass characteristics of heavy slaughter weight lambs: effects of sire breed and sex of lamb and relationships to serum metabolites and IGF-1. Animal Science, v.64, p.309-318, 1997.

Recebido em 3 de março de 2005 e aprovado em 21 de março de 2006 